\title{
Validation of an optimized HPLC/UV method for the quantification of flavonoids in lotus
}

\author{
Ju Sung Lee ${ }^{1}$, Leo Adrianne Paje ${ }^{1}$, Won-Hee Choi², Eun Ju Cho ${ }^{3}$, Hyun Young Kim4 ${ }^{4}$ Sonia D. Jacinto ${ }^{5}$ \\ and Sanghyun Lee ${ }^{1 *}$
}

\begin{abstract}
Flavonoids present in the leaves of lotus (Nelumbo nucifera) grown in different regions of South Korea (Yeongcheon, Haenam, and Seocheon) and at different harvest times (July to September) were determined. Flavonoid contents in lotus extracts were identified and analyzed using high-performance liquid chromatography (HPLC). The HPLC results revealed that the flavonoid contents of the lotus extracts varied at different harvesting times, with the highest content in July. Analysis of the flavonoid content in the leaves from the different regions showed the highest contents of isorhamnetin-3-O-glucoside, quercetin 3-O-glucuronide, and quercetin 3-O-glucoside in Yeongcheon, Korea, and highest contnts of rutin, myricetin, kaempferol 3-O-glucoside, and quercetin in Haenam, Korea. The HPLC method was validated and optimized to quantify quercetin 3-O-glucuronide; it showed good linearity $(1000-62.5 \mu \mathrm{g} / \mathrm{mL}$, $\left.r^{2}=0.9999\right)$, accuracy (106\%-108\%), and precision (RSD $\left.\leq 1.70 \%\right)$. Determination of flavonoid content in lotus is valuable for producing medicinal crops and identifying the optimal sources to increase the quantity of clinically available medicines.
\end{abstract}

Keywords: Flavonoid, HPLC, Method, Validation, Nelumbo nucifera

\section{Introduction}

Lotus (Nelumbo nucifera) has a wide distribution throughout North America, Australia, and East Asia [1]. The plant is used for various medicinal purposes and folk remedies in China [2] and is considered to be of cultural and historical importance in Egypt, India, and China [3-5] as it symbolizes perfection, purity, and beauty. In recent years, there have been reports on anti-viral [2], anti-obesity [6], anti-oxidant [7], and lipolytic [8] activities with simultaneous determinations of the components of lotus [9].

As oxygen free radicals, reactive oxygen species (ROS) contribute to aging and many related diseases [10]. The oxygen taken up via breathing is used by mitochondria within the body to generate energy, but they produce byproducts such as ROS which interfere with cell

\footnotetext{
*Correspondence: slee@cau.ac.kr

${ }^{1}$ Department of Plant Science and Technology, Chung-Ang University,

Anseong 17546, Republic of Korea

Full list of author information is available at the end of the article
}

function; their effects are long-lasting and can eventually lead to cell damage. An excess supply of oxygen produces free radicals that oxidize cells, destroying the cell structure, damaging DNA, and attacking the cell membrane. The resulting damaged cells grow and proliferate and eventually become cancer cells [11]. As ROS are highly unstable biochemical substances, they oxidize fat in the cells and blood to yield lipid peroxides, the main cause of aging. A potential solution to prevent cell damage caused by free radicals is the use of anti-oxidants such as flavonoids. Flavonoids are a large class of secondary metabolites that are widely present in plant species. They are important in human diet $[12,13]$ as they perform different metabolic functions are largely valued because of their anti-oxidant properties [14].

In this study, flavonoids were identified in the extracts of lotus leaves. A simultaneous analysis of the flavonoid content of lotus grown in different regions and at different harvesting times was also performed. Thus, the aim of this study was to evaluate whether lotus could be a 
rich natural source of flavonoids based on the measured concentrations.

\section{Materials and methods Plant materials}

The samples of lotus leaves were collected from different regions of South Korea (Haenam, Seocheon, and Yeongcheon) by Teazen Co., Korea. The samples were collected during the months of July, August, and September. A voucher specimen was deposited at Chung-Ang University, Korea.

\section{Instruments, chemicals, and reagents}

Chromatographic analysis was performed using an HPLC system (Agilent technology 1290 Infinity II) equipped with a pump, auto-sampler, and UV detector (Santa Clara, CA, USA). The flavonoids [myricetin (MYR), isorhamnetin 3-O-glucoside (I3Glc), quercetin (QUE), kaempferol 3-O-glucoside (K3Glc), quercetin 3-O-glucoside (Q3Glc), rutin (RUT), and quercetin 3-O-glucuronide (Q3Glu)] were prepared by the Natural Product Institute of Science and Technology (www.nist.re.kr), Anseong, Korea (Fig. 1). HPLC grade solvents (acetonitrile, methanol, and water) were obtained from J. T. Baker (Avantor, Radnor, PA, USA). Ethanol and acetic acid (99.7\%) were obtained from Samchun Pure Chemicals (Pyeongtaek, Korea).

\section{Sample preparation}

Dried lotus leaves $(15 \mathrm{~g})$ were extracted in distilled water using the Soxhlet procedure and dried using a freeze

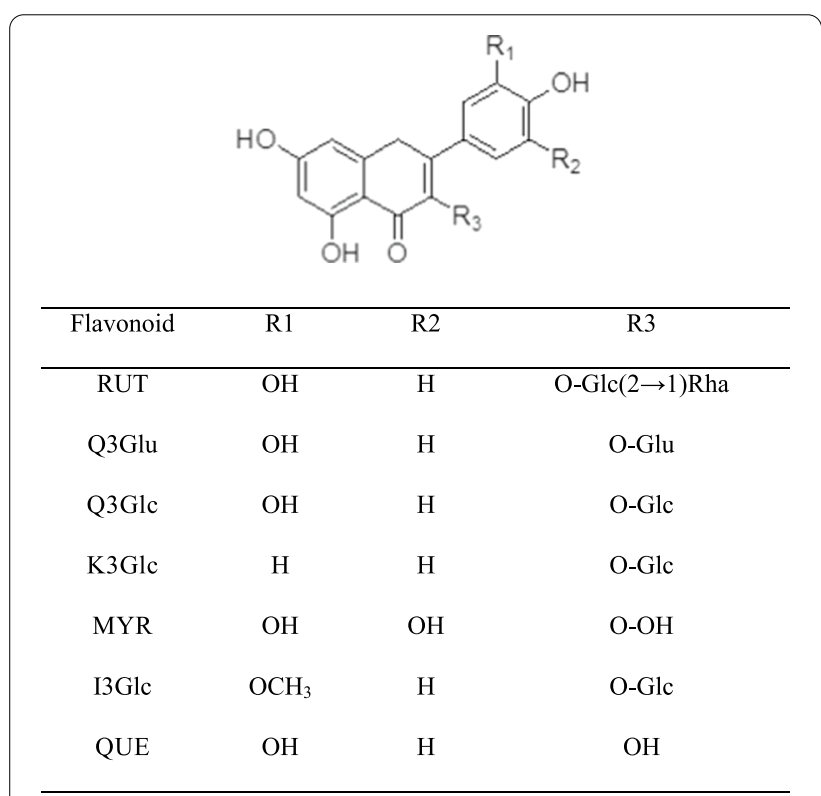

Fig. 1 Chemical structures of flavonoids in lotus dryer. This extract was dissolved in methanol $(\mathrm{MeOH})$ and filtered with a syringe filter $(0.45 \mu \mathrm{m}) . \mathrm{MeOH}$ was used to dissolve the compounds, and stock solutions $(0.125-1000 \mu \mathrm{g} / \mathrm{mL})$ were prepared.

\section{HPLC conditions}

Flavonoids were quantitatively analysed using a reversephase HPLC system with a UV system. An INNO C18 column $(25 \mathrm{~cm} \times 4.6 \mathrm{~mm}, 5 \mu \mathrm{m})$ was used to separate the compounds. The column temperature and flow rate were maintained at $35{ }^{\circ} \mathrm{C}$ and $1 \mathrm{~mL} / \mathrm{min}$, respectively. The injection volume was $10 \mu \mathrm{L}$, and the wavelength was detected at $350 \mathrm{~nm}$. The mobile phase with a gradient elution system composed of $0.5 \%$ acetic acid in water (A) and acetonitrile (B); $80 \% \mathrm{~A}$ at $0 \mathrm{~min}, 70 \% \mathrm{~A}$ at $30 \mathrm{~min}$, and $80 \% \mathrm{~A}$ at $35 \mathrm{~min}$.

\section{Method validation}

The validation of the HPLC method for Q3Glu was evaluated in terms of specificity, accuracy, linearity, and precision. To evaluate potential interference with the signals of the analytes, specificity was assessed. Using five concentrations of the standard mixture $(1000-0.1 \mu \mathrm{g} / \mathrm{mL})$, linearity was determined with triplicate injections/level. The chromatogram peak areas at $350 \mathrm{~nm}$ were plotted against the known concentrations of the standard solutions to construct the calibration curve. The standard curves for Q3Glu were analyzed using linear least-squares regression. For accuracy and precision validation, Q3Glu in the different standard mixtures $(1000,100$, and $10 \mu \mathrm{g} / \mathrm{mL})$ was used for intra- and inter-day precision analysis. For intra-day precision, the retention time and peak area of three different concentrations of the standard solutions were calculated in one day and expressed as the relative standard deviations (RSD \%). For inter-day precision, the RSD \% of the standard solutions was determined on three separate days. The recovery tests that analyzed the extracts were spiked with three concentrations of the standard mixture $(\mu \mathrm{g} / \mathrm{mg})$, and the \% recovery was used to determine the accuracy of the HPLC method.

\section{Calibration curves}

Each compound was dissolved in $\mathrm{MeOH}(1 \mathrm{mg} / \mathrm{mL})$ to preparare standard stock solutions. The selected stock solutions were serially diluted to the desired concentrations to construct calibration curves. All samples were dissolved in $\mathrm{MeOH}(20 \mathrm{mg} / \mathrm{mL})$. Prior to use, all examined solutions were filtered through a $0.45-\mu \mathrm{m}$ PVDF filter. The flavonoid calibration functions were calculated using the concentration $(\mathrm{X}, \mu \mathrm{g} / 10 \mu \mathrm{L})$, peak area $(\mathrm{Y})$, and mean values \pm standard deviation $(\mathrm{n}=5)$. 


\section{Results and discussion}

Flavonoids, a group of natural substances with variable phenolic structures, are found in vegetables, fruits, tea, flowers, grains, and wine. Lotus contains biologically effective flavonoids, including I3Glc, K3Glc, MYR, QUE, Q3Glc, Q3Glu, and RUT, which exhibit pharmacological activities [15]. Optimization and validation is important to facilitate the production of plant-derived health products [16-18] and source out the plant containing the most flavonoids where it can help increase its quantity in clinically available medicines.

Content of flavonoids in lotus leaves at different times (July to September) and from different regions (Yeongcheon, Haenam, and Seocheon in South Korea) were performed using HPLC. The calibration curve of the compounds was determined by plotting the peak area of the prepared concentrations and was calculated using

Table 1 Calibration curves of flavonoids in lotus

\begin{tabular}{llll}
\hline Compound & $\mathbf{t}_{\mathbf{R}}$ & Calibration equation & Correlation factor, $\boldsymbol{r}^{\mathbf{2}}$ \\
\hline RUT & 8.1 & $Y=917.46 X+3.4761$ & 0.9999 \\
Q3Glu & 8.9 & $Y=1158.4 X+28.395$ & 0.9999 \\
Q3GlC & 9.2 & $Y=1913.5 X+63.777$ & 1.0000 \\
K3GlC & 12.7 & $Y=1267.8 X+10.943$ & 0.9998 \\
I3GlC & 13.7 & $Y=865.57 X+4.8457$ & 1.0000 \\
MYR & 15.6 & $Y=1058.7 X-14.542$ & 0.9999 \\
QUE & 25.3 & $Y=1849.5 X-36.422$ & 0.9997
\end{tabular}

$t_{R}=$ retention times

$\mathrm{Y}=$ peak area, $\mathrm{X}=$ concentration of standard $(\mu \mathrm{g} / \mathrm{mL})$

$r^{2}=$ correlation coefficient for five data points in the calibration curve linear regression. The coefficient values $\left(r^{2}\right)$ of the compounds ranged from 0.9997 to 1.0000 (Table 1). For quantitative analyses, HPLC separation of the compounds was performed using a reverse phase system and gradient elution system (Fig. 2). Table 1 shows the standard calibration curves for the compounds. The HPLC method efficiently separated the compounds, and the retention times ranged from 8.1 to $25.3 \mathrm{~min}$. The effective wavelength for detecting the flavonoids and the main component of Q3Glu in a single run was $350 \mathrm{~nm}$ (Fig. 3).

The results suggested that the flavonoid contents in lotus extracts varied depending on the harvesting time (July, August, and September). The highest contents of K3Glc $(1.09 \mathrm{mg} / \mathrm{g})$, RUT $(1.46 \mathrm{mg} / \mathrm{g})$, I3Glc $(1.23 \mathrm{mg} / \mathrm{g})$, QUE $(1.55 \mathrm{mg} / \mathrm{g})$, and Q3Glu $(63.83 \mathrm{mg} / \mathrm{g})$ were found in July, whereas the highest contents of MYR $(1.16 \mathrm{mg} / \mathrm{g})$ and Q3Glc $(8.77 \mathrm{mg} / \mathrm{g})$ were found in August. Further, harvesting in July yielded a higher flavonoid content than in August and September. The flavonoid content from different regions was analyzed; it was the highest in Yeongcheon for Q3Glc (10.19 mg/g), I3Glc $(1.96 \mathrm{mg} / \mathrm{g})$, and Q3Glu (77.58 $\mathrm{mg} / \mathrm{g})$. In contrast, the content of K3Glc $(1.07 \mathrm{mg} / \mathrm{g})$, RUT $(1.71 \mathrm{mg} / \mathrm{g})$, QUE $(1.38 \mathrm{mg} / \mathrm{g})$, and MYR $(1.27 \mathrm{mg} / \mathrm{g})$ from Haenam was also high. The overall flavonoid content of lotus leaf extracts obtained from Yeongcheon was higher than from the other regions (Tables 2 and 3).

Our results corroborate previously reported data [19]. A previous study reported similar results with measured concentrations of hyperoside, Q3Glc, and K3Glc at 9.1, 4.6 , and $3.0 \mathrm{mg}$, respectively [19]. Another study showed

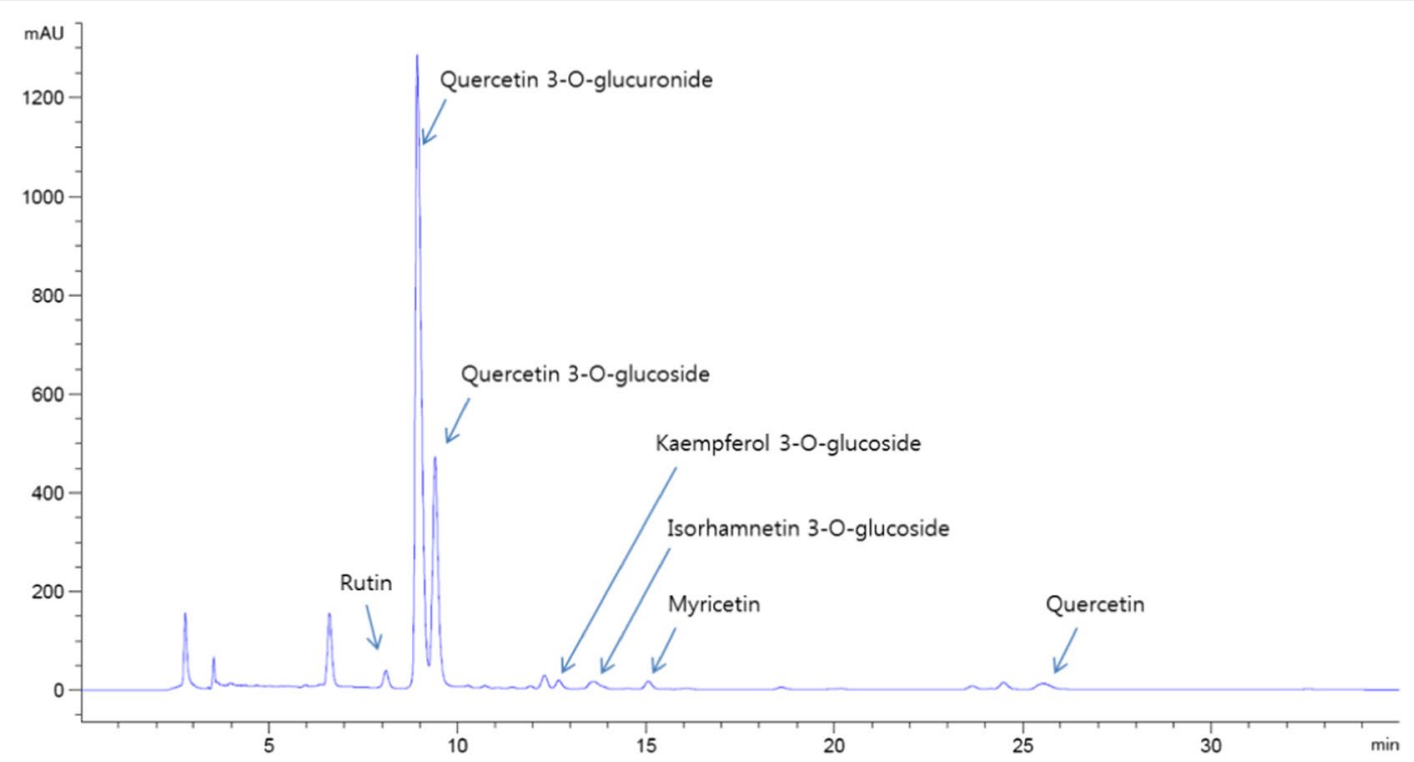

Fig. 2 HPLC profiling of the lotus extract 


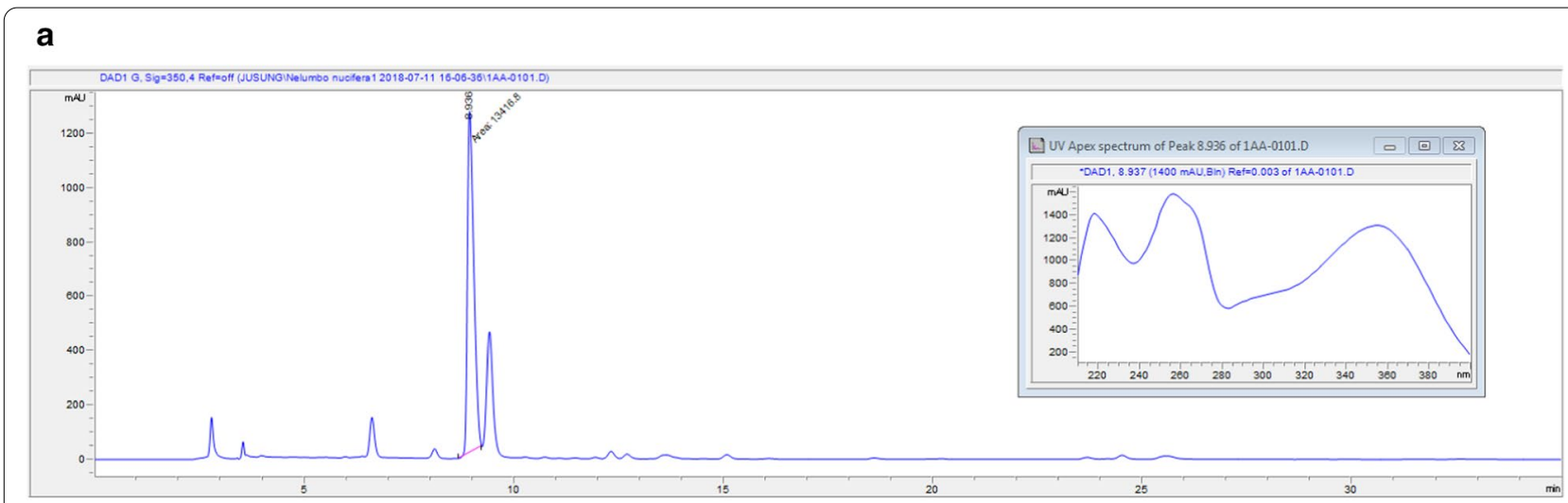

b

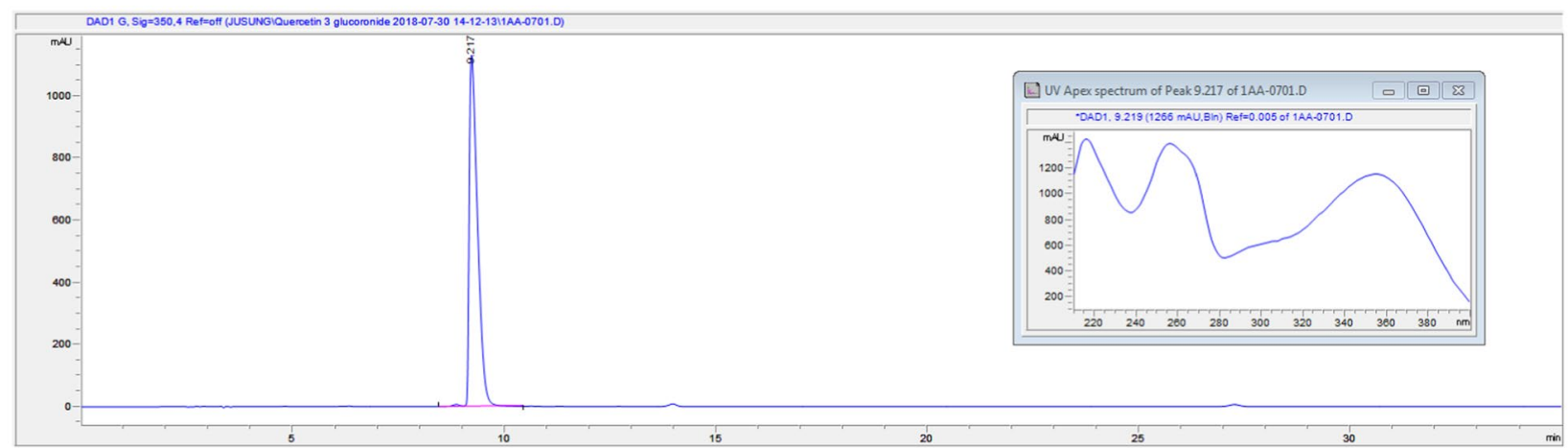

Fig. 3 HPLC chromatograms and specificity of lotus extract from Haenam (a) and Q3Glu (b)

Table 2 Contents of flavonoids in lotus at different harvesting times from Haenam region

\begin{tabular}{|c|c|c|c|c|c|c|c|}
\hline \multirow[t]{2}{*}{ Harvest } & \multicolumn{7}{|c|}{ Content (mg/g extract) } \\
\hline & RUT & Q3Glu & Q3Glc & K3Glc & I3Glc & MYR & QUE \\
\hline July & $1.46 \pm 0.15$ & $63.83 \pm 0.47$ & $5.67 \pm 0.10$ & $1.09 \pm 0.07$ & $1.23 \pm 0.00$ & $0.52 \pm 0.02$ & $1.55 \pm 0.16$ \\
\hline August & $1.19 \pm 0.01$ & $61.76 \pm 0.16$ & $8.77 \pm 0.16$ & $0.71 \pm 0.01$ & $1.22 \pm 0.28$ & $1.16 \pm 0.09$ & $1.27 \pm 0.02$ \\
\hline September & $0.40 \pm 0.05$ & $15.41 \pm 0.11$ & $1.77 \pm 0.07$ & $0.28 \pm 0.03$ & $0.53 \pm 0.04$ & $0.91 \pm 0.05$ & $0.82 \pm 0.03$ \\
\hline
\end{tabular}

Table 3 Contents of flavonoids in lotus from different regions harvested in July

\begin{tabular}{|c|c|c|c|c|c|c|c|}
\hline \multirow[t]{2}{*}{ Region } & \multicolumn{7}{|c|}{ Content (mg/g extract) } \\
\hline & RUT & Q3Glu & Q3Glc & K3Glc & I3Glc & MYR & QUE \\
\hline Yeongcheon & $0.79 \pm 0.01$ & $77.58 \pm 1.16$ & $10.19 \pm 0.18$ & $1.06 \pm 0.05$ & $1.96 \pm 0.06$ & $0.94 \pm 0.09$ & $1.07 \pm 0.03$ \\
\hline Haenam & $1.71 \pm 0.13$ & $54.27 \pm 0.29$ & $9.67 \pm 0.12$ & $1.07 \pm 0.01$ & $1.75 \pm 0.17$ & $1.27 \pm 0.03$ & $1.38 \pm 0.01$ \\
\hline Seocheon & $1.10 \pm 0.12$ & $74.02 \pm 0.66$ & $8.64 \pm 0.57$ & $0.65 \pm 0.01$ & $1.14 \pm 0.10$ & $0.78 \pm 0.05$ & $0.92 \pm 0.02$ \\
\hline
\end{tabular}

that Q3Glu (6.1 mg), obtained at a purity of 97.0\%, was the most dominant flavonoid in the lotus extract [20].

Intra- and inter-day precision levels were used to evaluate the method's precision in analyzing Q3Glu. These values were obtained within one day by triplicate analysis and over a 5-day period, respectively (Table 4). The coefficient of variation of Q3Glu ranged from 0.14 to $0.91 \%$ and 0.89 to $1.70 \%$ for intra- and inter-day precision, respectively. The obtained values were lower than $2 \%$, suggesting that the analytical method for quantifying 
Table 4 Intra- and inter-day precision for the determination of Q3Glu in lotus

\begin{tabular}{|c|c|c|c|c|c|}
\hline \multirow[t]{2}{*}{ Compound } & \multirow{2}{*}{$\begin{array}{l}\text { Spiked concentration } \\
(\mathrm{mg} / \mathrm{mL})\end{array}$} & \multicolumn{2}{|l|}{ Intra-day $(n=5)$} & \multicolumn{2}{|l|}{ Inter-day $(n=5)$} \\
\hline & & $\begin{array}{l}\text { Found concentration } \\
(\mathrm{mg} / \mathrm{g})\end{array}$ & RSD (\%) & $\begin{array}{l}\text { Found concentration } \\
(\mathrm{mg} / \mathrm{g})\end{array}$ & RSD (\%) \\
\hline \multirow[t]{3}{*}{ Q3Glu } & 20.0 & 34.32 & 0.14 & 34.79 & 1.70 \\
\hline & 17.5 & 34.91 & 0.91 & 34.83 & 0.89 \\
\hline & 15.0 & 35.32 & 0.73 & 34.50 & 1.47 \\
\hline
\end{tabular}

Table 5 Accuracy for the determination of Q3Glu in lotus

\begin{tabular}{|c|c|c|c|c|c|c|c|c|}
\hline \multirow[t]{2}{*}{ Compound } & \multirow{2}{*}{$\begin{array}{l}\text { Concentration (mg/ } \\
\mathrm{mL})\end{array}$} & \multicolumn{5}{|c|}{ Found content (mg) } & \multirow[t]{2}{*}{ Recovery (\%) } & \multirow[t]{2}{*}{ RSD (\%) } \\
\hline & & $1 s t$ & 2nd & $3 r d$ & 4th & 5 th & & \\
\hline \multirow[t]{3}{*}{ Q3Glu } & 0.25 & 0.28 & 0.27 & 0.27 & 0.27 & 0.28 & 108.61 & 1.22 \\
\hline & 0.5 & 0.53 & 0.53 & 0.54 & 0.54 & 0.54 & 106.79 & 1.14 \\
\hline & 1 & 1.07 & 1.06 & 1.07 & 1.08 & 1.09 & 107.41 & 1.12 \\
\hline
\end{tabular}

Q3Glu from the lotus extract showed good precision (Table 4).

Recoveries for Q3Glu were examined to validate the accuracy of the analytical method. Three different concentrations were analyzed five times. The recovery of Q3Glu ranged from 106.79 to $108.61 \%$, indicating that the analytical method used to quantify Q3Glu exhibited good accuracy (Table 5).

In conclusion, the flavonoids in lotus are important in producing medicinal crops, and analyses to identify optimal sources can increase the quantity of clinically available medicines. Additionally, the majority of the flavonoid content has been obtained from lotus grown domestically, for example, in Yeongcheon. This suggests that lotus grown in Yeongcheon, South Korea, can be an internationally competitive source in developing lotusderived products as it contained the highest flavonoid contents among the lotus from other places.

\section{Authors' contributions}

JSL experiments of specificity, accuracy, and precision; LAP HPLC analysis and HPLC profiling; W-HC harvesting and collecting samples and experimental design; EJC and HYK, content analysis and data reading; SDJ, data interpretation and English writing; SL, experimental design and English writing. All authors read and approved the final manuscript.

\section{Funding}

This research was supported by the Chung-Ang University Research Grants in 2018 and the Ministry of Trade, Industry \& Energy (MOTIE), Korea Institute for Advancement of Technology (KIAT) through the Encouragement Program for The Industries of Economic Cooperation Region (P0000810).

\section{Availability of data and materials}

Not applicable.

Competing interests

There is so conflict of interests.

\section{Author details}

1 Department of Plant Science and Technology, Chung-Ang University, Anseong 17546, Republic of Korea. ${ }^{2}$ R\&D Center, Teazen Co, Anyang 14067 , Republic of Korea. ${ }^{3}$ Department of Food Science and Nutrition, Pusan National University, Busan 46241, Republic of Korea. ${ }^{4}$ Department of Food Science, Gyeongnam National University of Science and Technology, Jinju 52725, Republic of Korea. ${ }^{5}$ Institute of Biology, University of the Philippines, 1101 Diliman, Quezon, Philippines.

Received: 20 October 2020 Accepted: 25 November 2020

Published online: 08 December 2020

\section{References}

1. Chen S, Wu BH, Fnag JB, Liu YL, Zhang HH, Fang LC, Guan L, Li SH (2012) Analysis of flavonoids from lotus (Nelumbo nucifera) leaves using high performance liquid chromatography/photodiode array detector tandem electrospray ionization mass spectrometry and an extraction method optimized by orthogonal design. J Chromatogr A 1227:145-153

2. Kashiwada Y, Aoshima A, Ikeshiro Y, Chen YP, Furukawa H, Itoigawa M, Fujioka T, Mihashi K, Cosentino LM, Morris SL (2005) Anti-HIV benzylisoquinoline alkaloids and flavonoids from the leaves of Nelumbo nucifera, and structure-activity correlations with related alkaloids. Bioorg Med Chem 13:443-448

3. Harer WB (1985) Pharmacological and biological properties of the Egyptian lotus. J Am Res Center Egypt 22:49-54

4. Karki R, Jung MA, Kim KJ, Kim DW (2012) Inhibitory effect of Nelumbo nucifera (Gaertn.) on the development of atopic dermatitis-like skin lesions in NC/Nga mice. Evid Bas Complement Altern Med 7:53568

5. Karki R, Jeon ER, Kim DW (2012) Nelumbo nucifera leaf extract inhibits neointimal hyperplasia through modulation of smooth muscle cell proliferation and migration. Nutr 29:268-275

6. Ono Y, Hattori E, Fukaya Y, Imai S, Ohizumi Y (2006) Anti-obesity effect of Nelumbo nucifera leaves extract in mice and rats. J Ethnopharmacol 106:238-244

7. Wu MJ, Wang L, Weng CY, Yen JH (2003) Antioxidant activity of methanol extract of the lotus leaf (Nelumbo nucifera Gertn.). Am J Chin Med 31:687-698

8. Ohkoshi E, Miyazaki H, Shindo K, Watanabe H, Yoshida A, Yajima H (2007) Constituents from the leaves of Nelumbo nucifera stimulate lipolysis in the white adipose tissue of mice. Planta Med 73:1255-1259 
9. Ryu G, Weon JB, Yang WS, Ma CJ (2017) Simultaneous determination of four compounds in a Nelumbo nucifera seed embryo by HPLC-DAD. J Spectrosc. https://doi.org/10.1155/2017/6426394

10. Nita M, Grzybowski A (2016) The role of the reactive oxygen species and oxidative stress in the pathomechanism of the age-related ocular diseases and other pathologies of the anterior and posterior eye segments in adults. Oxid Med Cell Longev. https://doi.org/10.1155/2016/3164734

11. Pham LA, Hua H, Pham C (2008) Free radicals, antioxidants in disease and health. Int J Biomed Sci 4:89-96

12. Agati G, Azzarello E, Pollastri S, Tattini M (2012) Flavonoids as antioxidants in plants: location and functional significance. Plant Sci 196:67-76

13. Cook NC, Samman S (1996) Flavonoids-chemistry, metabolism, cardioprotective effects, and dietary sources. J Nutr Biochem 7:66-76

14. Perez-Vizcaino F, Fraga CG (2018) Research trends in flavonoids and health. J Bio Chem Phys 646:107-112

15. Naveen P, Lingaraju HB, Anitha PKS (2017) Simultaneous determination of rutin, isoquercetin, and quercetin flavonoids in Nelumbo nucifera by high-performance liquid chromatography method. Int J Pharm Investig 7:94-100

16. Rodriguez JP, Lee J, Park JY, Kang KS, Hahm D-H, Lee SC, Lee S (2017) HPLC-UV analysis of sample preparation influence on flavonoid yield from Cirsium japonicum var. maackii. Appl Biol Chem 60:519-525
17. Lee JS, Quilantang NG, Nam K-W, Piao X-L, Chung MJ, Lee S (2018) Optimization of extraction conditions and quantitative analysis of isoquercitrin and caffeic acid from Aster scaber. Nat Prod Sci 24:199-205

18. Lee JS, Quilantang NG, Hahm D-H, Kang KS, Jacinto SD, Choi Y-J, Lee SC, Lee S (2020) Optimization of extraction conditions of continentalic and kaurenoic acids from Aralia continetalis by HPLC/UV and their validation. J Chromatogr Sci 58:672-677

19. Zhu MZ, Wu W, Jiao LL, Yang PF, Guo MQ (2015) Analysis of flavonoids in lotus (Nelumbo nucifera) leaves and their antioxidant activity using macroporous resin chromatography coupled with LC-MS/MS and antioxidant biochemical assays. Biochem Ass Molec 20:10553-10565

20. XuY, Simon JE, Welch C, Wightman JD, Ferruzzi MG, Ho L (2011) Survey of polyphenol constituents in grapes and grape-derived products. J Agric Food Chem 59:10586-10593

\section{Publisher's Note}

Springer Nature remains neutral with regard to jurisdictional claims in published maps and institutional affiliations.

\section{Submit your manuscript to a SpringerOpen ${ }^{\odot}$ journal and benefit from:}

- Convenient online submission

- Rigorous peer review

- Open access: articles freely available online

- High visibility within the field

- Retaining the copyright to your article

Submit your next manuscript at $\boldsymbol{\nabla}$ springeropen.com 